\title{
Novas formas de ocupação, do trabalho e condições
}

\section{New forms of occupation, work and conditions}

\author{
VALERIA BERTONCELO* \\ LUCIANO JUNQUEIRA**
}

\section{Resumo}

O sentido do trabalho foi modificado ao longo do tempo, deixou de ser um encargo, castigo para se tornar uma forma de sobrevivência pelo exercício de uma atividade laboral. O avanço tecnológico traz novas formas de ocupação e de significação do trabalho para o indivíduo e inclusive para as organizações. Sob o âmbito das democracias, o avanço tecnológico traz à tona o futuro do emprego em uma economia globalizada com taxas de crescimento estáveis. A pesquisa tem por objetivo o levantamento da produção acadêmica, no Brasil, para os últimos 15 anos (20012015) em revistas de Administração com abordagem crítica. Os resultados da pesquisa demonstram o volume de produção que é relativamente menor em comparação com as demais áreas do conhecimento, corroborando com outros resultados de que grande parte das pesquisas em Administração é voltada para a gestão, a eficiência, a produtividade e pouco para os estudos críticos com visão emancipatória.

Palavras-chave: Trabalho. Tecnologia. Organizações.

\section{Abstract}

The meaning of work has changed over time, from being a burden, punishment to becoming a way of survival through the exercise of a work activity. The technological advance brings

* Pontificia Universidade Catolica de São Paulo. valrbertoncelo@hotmail.com .

* Pontificia Universidade Catolica de São Paulo. Possui graduação em Ciências Sociais pela Universidade de São Paulo (1969). Atualmente é professor Titular da Pontifícia Universidade Católica de São Paulo, Coordenador do Núcleo de Estudos Avançados do Terceiro Setor- NEATS/PUCSP. junq@pucbr.sp . 
new forms of occupation and of signification of the work for the individual and even for the organizations. Under democracies, technological advancement brings forth the future of employment in a globalized economy with stable growth rates. The research aims to survey the academic production in Brazil for the last 15 years (2001-2015) in Management magazines with a critical approach. The results of the research show that the volume of production is relatively smaller in comparison with the other areas of knowledge, corroborating with other results that a great part of the research in Administration is focused on management, efficiency, productivity and little for the critical studies with emancipatory vision.

Key-words: Work. Occupation. Technology. Organizations.

\section{INTRODUÇÃO}

As novas tecnologias e as condições de trabalho estão entre as temáticas de estudos críticos na administração e para os estudos do futuro e ou futuristas. O avanço da tecnologia nos processos de produção traz a substituição da mão de obra de trabalho, mas também, produz novas formas de trabalho e de contratação, como resposta alternativa. É a redução da complexidade e pela produtividade superior.

A imprevisibilidade sobre o impacto das tecnologias a respeito do futuro do trabalho traz a temática para a discussão de estudiosos futuristas acerca do que será o trabalho para os próximos trinta anos e como será a administração dessa transição. É importante lembrar que, hoje, a força de trabalho global total é estimada em seis bilhões, categorizados em dois bilhões de empregados, outros dois bilhões são os que trabalham por conta própria, representando uma nova forma de trabalho; outros um bilhão alocados na economia informal dada a exclusão social ou por não terem tido a sua emancipação, e finalmente, outro um bilhão de desempregados ou em transição que ainda não migraram para outras formas de trabalho dada a incerteza da economia na geração de novos postos de trabalho. Esta é a visão prospectiva sobre a temática do trabalho.

Sob a perspectiva dos estudos críticos da administração, a abordagem do trabalho é representada pelas condições de trabalho propiciada pelas novas formas de trabalho, mecanismos de contro- 
le para a medição da produtividade e cumprimento das horas de contrato de trabalho, mas também, da demonstração da necessidade de uma representação ideológica que permita o questionamento das estruturas existentes, bem como, a busca constante de emancipação do indivíduo e ou trabalhador. Isso é decorrente das bases epistemológicas dos estudos críticos, exemplificando: humanismo radical, marxismo heterodoxo e escola de Frankfurt, mas também, das escolas denominados pós-estruturalistas, que centram acerca da temática da burocracia flexível, das teorias pós-fordistas, dos meios de comunicação, da qualidade total, da reengenharia e das novas tecnologias.

A temática sobre trabalho e suas derivações são relevantes para os estudos organizacionais, bem como, para as classes sociais que sobrevivem da remuneração laboral, contraprestação de serviços. Sob a ótica dos estudos críticos da administração, esta pesquisa tem por objetivo analisar se as publicações entre 2001 a 2015 a respeito das novas formas de ocupação e suas condições de trabalho e, eventualmente, têm uma razão emancipatória, irrompem o indivíduo e a sociedade, transformam as relações de trabalho ao longo do tempo.

\section{REFERENCIAL TEÓRICO}

A utilização do termo trabalho pode ser observada em um contexto histórico-filosófico-religioso com o significado de sacrifício, esforço, lide. No Antigo Testamento, representava uma punição. Para a antiguidade, o trabalho era realizado pelos escravos e os cidadãos livres tinham direito às atividades políticas e ao ócio. Tempos depois, na Idade Média, a estratificação da sociedade feudal em clero, nobreza e servos, dava ao último a obrigação pelo trabalho a ser aplicado nas terras e, também, pela fidelidade ao seu suserano. Durante muito tempo, o tempo dedicado ao trabalho era confundido com as atividades domésticas, pois eram feitos em casa, em família e os filhos. O conhecimento desse ofício era passado às futuras gerações.

A partir do século $\mathrm{XV}$, o significado de trabalho sofreu profundas alterações face à Reforma Religiosa e ao Renascimento Cultural, estabelecendo o conceito de que o trabalho era salvação, mas o ócio a condenação; a promoção de novas atividades por meio das artes 
e da ciência contribuíram para com o significado de libertação, respectivamente. Por fim, o Iluminismo trouxe a ideia de valor para o trabalho, uma vez que representava a possibilidade de ascensão social por meio do exercício laboral. No século XVIII, com a Revolução Industrial, surge a produção em larga escala, trabalho mecanizado, especializado e os salários pela venda da força de trabalho. Este foi um tempo em que os trabalhadores eram submetidos a extensas jornadas de trabalho, trazendo à tona a exploração e as perversidades da relação do trabalho. No século $X X$, o trabalho tinha uma associação significativa aos conceitos de produtividade e de produção em escala, propiciados pelos trabalhos científicos de Taylor e de Henri Ford.

Para o século XXI, o trabalho ainda tem o sentido de obrigação, dever, responsabilidade, porém, com uma perspectiva psicológica e cognitiva da construção das percepções sobre o termo trabalho para o indivíduo. O trabalho faz parte do cotidiano do indivíduo, uma vez que passa a maior parte do tempo em exercício da função e nas organizações.

O trabalho tem sido estudado em diversas áreas, como: Sociologia Industrial, Teoria Organizacional, Administração, Relações Industriais, Psicologia Social do Trabalho e Sociologia das Ocupações (THOMPSON, 1989). A obra The Nature of Work: An Introduction to Debates on the Labour Process faz um debate contemporâneo sobre a desqualificação e a degradação do trabalho, além da crítica às estruturas de controle e ao taylorismo. Também, aborda a legitimação, autorização de trabalho e os efeitos da divisão do trabalho em classes de gênero.

A importância ou a significação do trabalho para o indivíduo tornou-se objeto de estudo a partir da mudança das características do trabalho ao longo do tempo, principalmente, com o advento da sociedade ancorada na informação. Nesse modelo, a informação é geradora do desenvolvimento social e econômico, ao contrário de outras décadas que a economia era fundamentada no consumo e na utilização de energia barata. O impacto tecnológico produzido para o trabalho foi da diferenciação das atividades complexas que requerem trabalhadores especializados na produção de informação para o suporte das decisões e da utilização de computadores, robôs para aquelas consideradas simples e substituíveis. 
Na década de 1980, um estudo sobre o significado de trabalho ou The meaning of Working International Research Team, foi desenvolvido por um grupo de pesquisadores, onde, estabeleceram o conceito por meio do estabelecimento de três conceitos: i) centralidade do trabalho - representada pela importância que o trabalho tem na vida do indivíduo, a partir de uma convicção acerca do valor do trabalho, ii) normas sociais - pressão da sociedade sobre o comportamento do indivíduo e iii) os resultados objetivos valorizados do trabalho, como fonte de trabalho, função intrínseca e social (MOW, 1987).

As novas formas de trabalho são decorrentes de movimentos da economia, principalmente, quando há declínio das taxas de crescimento, por conseguinte, instabilidade na cadeia insumo-produçãoconsumo. Da necessidade de adaptação das organizações, emergem alternativas de contratação de mão de obra. Por sua vez, é possível que haja a precarização das condições de trabalho. Cavalcante \& Prédes (2010) observam que é necessário definir o termo precarização das condições de trabalho, pois isso tem correspondência desde os direitos trabalhistas, benefícios sociais, higiene e segurança no trabalho, proteção sindical.

Nestes tempos de economias em crise, há de se mencionar como precarização a redução dos salários percebidos para a manutenção do emprego e da colocação de postos de trabalhos em regime de contratação parcial para fazer frente às tendências de retração econômica. Costa (2003, 2007 e DA COSTA, 2007) indica novas relações de trabalho nas últimas décadas, no Brasil, impulsionadas pela redução do número de empregos formais. Tal situação, permite que as organizações abriguem novas formas de contrato de trabalho e ou vínculos com os seus colaboradores, sendo o primeiro, aquele, dado como tradicional, pois utiliza as formas contratuais previstas em CLT - Consolidação das Leis do Trabalho. Em segundo estão os contratos terceirizados, firmados com profissionais altamente especializados que não fazem parte da atividade-fim e, por isso, não se justifica sua contratação, permitindo às organizações o acesso a especialistas com custos menores. Em terceiro, finalmente, estão os temporários, que são os mais vulneráveis entre os trabalhadores, pois convivem com a incerteza nas relações de trabalho. A flexibilização do contrato de trabalho é uma nova condição e relação de 
trabalho nas organizações, muitas vezes, não representa equidade entre as partes, mas necessidade de uma delas. A palavra flexibilidade, de acordo com Sennet (2004) foi inserida no vocabulário inglês, no século $X V$, cujo sentido foi da capacidade de ceder e voltar à sua forma original. Essa definição derivou da observação de uma árvore que se dobrasse ao vento, voltaria a sua posição normal. É o reinventar das organizações, produzindo novas relações e estruturas de poder.

As transformações que afetam o mundo do trabalho por um processo de racionalização e a consequente alienação do trabalhador, face à disponibilidade de capital, impulsionam a crescente valorização da atividade financeira, a difusão de tecnologias da informação e comunicação, nova divisão internacional do trabalho, preponderância da política econômica liberal e reestruturação das empresas na lógica da racionalização flexível. O trabalhador se vê, portanto, imerso em uma nova realidade que torna o trabalho cada vez mais abstrato, precarizado. O trabalho passa a ter um significado de sobrevivência para o indivíduo e não como parte integrante do seu desenvolvimento (BENÍCIO DE MELLO, MARÇAL, FONSECA, 2009).

Estudos sobre o trabalho nas organizações, com abordagem que o questionamento das estruturas, do desenvolvimento progressivo das responsabilidades sociais do indivíduo pode ser considerado restrito, face à dependência econômica nas relações e na atual significação do termo trabalho para o indivíduo.

De acordo com Fuornier e Grey (2000), os estudos com vieses de questionamento às estruturas que levem à independência do indivíduo requerem a contextualização dos seguintes quesitos: a) promulgação de uma visão desnaturalizada - as teorias tradicionais constroem a realidade das organizações como uma realidade concreta, entretanto, são uma construção sócio-histórica, de acordo com os estudos críticos da administração; b) intenções desvinculadas do desempenho econômico financeiro das organizações - o desenvolvimento de uma pesquisa crítica não se preocupa com a geração de conhecimento para a eficiência e melhoria do desempenho econômico financeiro de uma organização, mas da tentativa de emancipação do indivíduo dos mecanismos de opressão; c) representam um ideal de emancipação - têm intenção de promover o potencial da 
consciência humana para refletir de maneira crítica sobre as práticas opressivas, contribuindo para a autonomia e responsabilidade das pessoas. A autonomia em questão é a capacidade dos seres humanos produzirem julgamentos que não sejam impedidos ou deformados por dependências sociais inúteis associadas à subordinação e às desigualdades de riqueza, de poder e de conhecimento. E, responsabilidade, que é o desenvolvimento de uma consciência de nossa interdependência social, por conseguinte, a compreensão de nossa responsabilidade coletiva para com os outros.

Guerreiro Ramos $(1981,1989)$ argumenta que a restrição do tempo dispendido nas organizações para a realização de outras atividades, em outros tipos de organização, pode contribuir para a emancipação do indivíduo.

Vergara e Gomes (2003) pesquisaram sobre as condições de trabalho no ambiente organizacional sob duas perspectivas: interação e controle. Nesta pesquisa, corroboram o entendimento de como o layout aberto dos escritórios facilita a comunicação entre os diversos níveis hierárquicos da organização, mas por sua vez, promovem para os gestores condições ideais para o exercício do controle e da produtividade. Esse conceito de eliminação das barreiras visuais, com uma ideia de integração arquitetônica dos ambientes, mas, em verdade, reduz a sociabilidade, pois todos são mutuamente vigiados, independentemente de suas categorias hierárquicas e a única forma de proteção, entre os mesmos, é o silêncio (SENNET, 1988).

\section{Metodologia}

Foi adotado o levantamento bibliográfico durante o período de 2001 a 2015 para as revistas RAP, RAUSP, O\&S, RAC e RAE -eletrônica, por meio da ferramenta de pesquisa do portal $\underline{w} w \mathbf{W}$. spell.org.br. A estratificação dos textos adotou o seguinte critério: i) seleção dos artigos por intermédio da busca textual em palavraschave; ii) Leitura e análise de conteúdo dos resumos dos artigos pré-selecionados; iii) seleção dos artigos que perfazem a categoria de estudos críticos das organizações; iv) levantamento da bibliografia utilizada; v) síntese dos resultados identificados.

A busca textual realizada no campo de palavras-chave teve por objeto a procura pelas seguintes palavras: ocupações, novas tecnolo- 
gias, condições de trabalho e trabalho. Como parte da estratificação dos textos levantados, procedeu-se à revisão do referencial teórico e à análise dos resumos, onde se buscou a identificação de conteúdo bibliográfico à crítica das novas formas de trabalho e suas condições, como parte integrante dos Estudos Críticos Organizacionais. Para isso, utilizaram-se os estudos de Fuornier e Grey (2000), onde preconizam que os estudos críticos têm por objetivo o questionamento das estruturas organizacionais e que tenham contribuição para com a independência do indivíduo, com isso, não há uma preocupação primária para com a geração de conhecimento aplicável à eficiência e melhoria do desempenho econômico financeiro de uma organização, mas, possibilidade da emancipação do indivíduo dos mecanismos de opressão. Também, foram apoio de pesquisa os estudos de Davel e Alcadipany (2000), que se constituíram em uma pesquisa bibliográfica sobre as principais temáticas trabalhadas pelos autores brasileiros de estudos críticos em publicações brasileiras nos anos 80 e 90.

\section{RESULTADOS}

O levantamento das publicações para o período base de 20012015 resultou em 3.365 artigos publicados nas revistas: RAP, RAUSP, O\&S, RAC e RAE-eletrônica. A aplicação da etapa metodológica da categorização de estudos críticos das organizações e do levantamento das palavras-chave resultou em uma estratificação da amostra em 515 artigos. Nessa etapa, as publicações não tiveram análise para a contribuição para com os Estudos Críticos de Administração, como preterido por Fuornier e Grey (2000) e Davel e Alcadipany (2000). A seguir, o Quadro 1 sumariza os resultados da aplicação da $1^{\underline{a}}$ a $4^{\underline{a}}$. etapas metodológicas. 
Quadro 1: Participação das publicações sobre "Novas formas de ocupação e suas condições de trabalho" nos periódicos RAC, RAE-Eletrônica, RAP, RAUSP e OES, no período de 2001 a 2015

\begin{tabular}{|l|l|l|l|}
\hline Publicação & $\begin{array}{l}\text { Total de Arti- } \\
\text { gos }\end{array}$ & $\begin{array}{l}\mathbf{1}^{\text {a }} \text { e 2 } \mathbf{2}^{\text {a }} \text { Etapa } \\
\text { Metodológica }\end{array}$ & $\begin{array}{l}3^{\text {a }} \text { e } 4^{\text {a }} \text { Etapa } \\
\text { Metodológica }\end{array}$ \\
\hline RAP & 901 & 147 & 1 \\
\hline RAC & 737 & 96 & 0 \\
\hline RAE-E & 616 & 36 & 1 \\
\hline O\&S & 565 & 147 & 8 \\
\hline RAUSP & 546 & 89 & 6 \\
\hline Total & 3.365 & $5 \mathbf{5 1 5}$ & $\mathbf{1 6}$ \\
\hline
\end{tabular}

Fonte: preparado pelos autores

A partir desses resultados, as publicações seguiram para a terceira etapa, com o objetivo da avaliação da contribuição para com os Estudos Críticos da Administração. Para isso, a leitura das publicações teve como objetivo identificar se a pesquisa promoveu o seguinte: a) uma visão desnaturalizada; b) intenções desvinculadas do desempenho econômico financeiro das organizações; c) representam um ideal de emancipação do indivíduo na sociedade e nas organizações, resultando em 16 artigos sobre o tema de uma crítica às organizações e à sociedade a respeito de novas formas e trabalho e suas condições.

O Quadro 2 - Publicações sobre "Novas formas de trabalho e suas condições" nos periódicos: RAC, RAE-Eletrônica, RAP, RAUSP e O\&S exemplifica os artigos cujo conteúdo bibliográfico, também, será objeto desta pesquisa. 
Quadro 2 - Publicações sobre "Novas formas de trabalho e suas condições" nos periódicos RAC, RAE-Eletrônica, RAP, RAUSP e OES, no período de 2001 a 2015

\begin{tabular}{|c|c|c|c|c|}
\hline & Título & Autores & Periódico & Ano \\
\hline 1 & $\begin{array}{l}\text { Administração e Teorias das Organi- } \\
\text { zações Contemporâneas: rumo a um } \\
\text { humanismo-radical crítico? }\end{array}$ & Omar Aktouf & O\&S & 2001 \\
\hline 2 & $\begin{array}{l}\text { Escritórios abertos: interação ou } \\
\text { controle? }\end{array}$ & $\begin{array}{l}\text { Sylvia Constant Ver- } \\
\text { gara, Ana Paula Cortat } \\
\text { Zambrotti Gomes }\end{array}$ & RAP & 2003 \\
\hline 3 & $\begin{array}{l}\text { A inserção da racionalidade ético- } \\
\text { comunicativa na práxis-empresarial: } \\
\text { possibilidades e limites }\end{array}$ & $\begin{array}{l}\text { Reynaldo Josué de } \\
\text { Paula }\end{array}$ & O\&S & 2005 \\
\hline 4 & $\begin{array}{l}\text { Trabalho, controle e resistências nas } \\
\text { sociedades capitalistas: uma perspecti- } \\
\text { va organizacional }\end{array}$ & $\begin{array}{l}\text { Jean Martins de Souto, } \\
\text { Rúbia da Silva }\end{array}$ & O\&S & 2005 \\
\hline 5 & $\begin{array}{l}\text { Desconstruindo temas e estratégias da } \\
\text { Administração moderna: uma leitura } \\
\text { pós-moderna do mundo de Dilbert }\end{array}$ & $\begin{array}{l}\text { Neusa Rolita Cavedon, } \\
\text { Jorge Francisco Bertine- } \\
\text { tti Lengler }\end{array}$ & O\&S & 2005 \\
\hline 6 & $\begin{array}{l}\text { Reestruturação produtiva e precariza- } \\
\text { ção do trabalho: o mundo do trabalho } \\
\text { em transformação }\end{array}$ & $\begin{array}{l}\text { José Henrique de Fa- } \\
\text { ria, Antonio Kremer }\end{array}$ & RAUSP & 2005 \\
\hline 7 & $\begin{array}{l}\text { Impactos da mobilização da subje- } \\
\text { tividade nos processos de formação } \\
\text { profissional e sindical }\end{array}$ & $\begin{array}{l}\text { Maria Leticia Corrêa, } \\
\text { Solange Maria Pimenta }\end{array}$ & RAEletronica & 2006 \\
\hline 8 & $\begin{array}{l}\text { O contrato psicológico como ferra- } \\
\text { menta para a gestão de pessoas }\end{array}$ & $\begin{array}{l}\text { Leticia Fantinato } \\
\text { Menegon, Tania } \\
\text { Casado }\end{array}$ & RAUSP & 2006 \\
\hline 9 & $\begin{array}{l}\text { O pai que não é patrão: vivência de } \\
\text { sujeitos terceirizados no Ministério } \\
\text { Público do Estado do Rio Grande do } \\
\text { Sul }\end{array}$ & $\begin{array}{l}\text { Silvia Generali da } \\
\text { Costa }\end{array}$ & O\&S & 2007 \\
\hline 10 & $\begin{array}{l}\text { Cidadania e desemprego no Brasil } \\
\text { contemporâneo: uma reflexão a partir } \\
\text { das categorias de subjetividade do } \\
\text { indivíduo, mero-indivíduo e pessoa }\end{array}$ & $\begin{array}{l}\text { Maria Cecília Pereira, } \\
\text { José Roberto Pereira, } \\
\text { Mozar José de Brito }\end{array}$ & O\&S & 2007 \\
\hline 11 & $\begin{array}{l}\text { Os sentidos do trabalho precarizado } \\
\text { na Metrópolis: fato e ficção! }\end{array}$ & $\begin{array}{l}\text { Sérgio Carvalho Be- } \\
\text { nício de Mello, Maria } \\
\text { Christianni Coutinho } \\
\text { Marçal, Francisco Ri- } \\
\text { cardo Bezerra Fonsêca }\end{array}$ & O\&S & 2009 \\
\hline 12 & $\begin{array}{l}\text { Contratos psicológicos e terceirização: } \\
\text { um estudo das relações entre vínculos } \\
\text { e as práticas de gestão de pessoas }\end{array}$ & $\begin{array}{l}\text { Mino Correia Rios, } \\
\text { Sônia Maria Guedes } \\
\text { Gondim }\end{array}$ & O\&S & 2010 \\
\hline
\end{tabular}




\begin{tabular}{|c|c|c|c|c|}
\hline & Título & Autores & Periódico & Ano \\
\hline 13 & $\begin{array}{l}\text { Contratos psicológicos: uma revisão } \\
\text { da literatura }\end{array}$ & $\begin{array}{l}\text { Leticia Fantinato } \\
\text { Menegon, Tania } \\
\text { Casado }\end{array}$ & RAUSP & 2012 \\
\hline 14 & $\begin{array}{l}\text { Análise de fatores associados ao signi- } \\
\text { ficado do trabalho }\end{array}$ & $\begin{array}{l}\text { Sergio Hideo } \\
\text { Kubo, Maria Aparecida } \\
\text { Gouvêa }\end{array}$ & RAUSP & 2012 \\
\hline 15 & $\begin{array}{l}\text { Humor na Internet: trabalhadores } \\
\text { utilizam nova estratégia para protestar } \\
\text { contra demissões e terceirizações }\end{array}$ & $\begin{array}{l}\text { Raquel Alves } \\
\text { Furtado, Alexandre de } \\
\text { Pádua Carrieri, Paula } \\
\text { Fernandes Furbino } \\
\text { Bretas }\end{array}$ & RAUSP & 2014 \\
\hline 16 & $\begin{array}{l}\text { Contratos flexíveis de trabalho: } \\
\text { diferentes perfis de trabalhadores } \\
\text { qualificados brasileiros }\end{array}$ & $\begin{array}{l}\text { Marcia Carvalho de } \\
\text { Azevedo, Maria José } \\
\text { Tonelli, André Luis } \\
\text { Silva }\end{array}$ & RAUSP & 2015 \\
\hline
\end{tabular}

Fonte: preparado pelos autores

O referencial teórico das publicações é bem diversificado e, também, utiliza outras ciências sociais para a composição do referencial teórico, como demonstrado no Quadro 4. Para fins da abordagem crítica sobre a abordagem de controle, são utilizados os estudos de Foucault em suas obras: Microfísica do poder (1979), Vigiar e punir (1987). Nesses estudos, são utilizadas as metáforas da prisão, que têm sua origem no projeto panóptico de Benthan (2000). Este fez a concepção de uma prisão ideal sob o aspecto econômico e de controle. Nos dias atuais, a metáfora tem aplicação em temas sobre disciplina e controle. Também, é empregado para o conceito arquitetônico de escritórios com espaços livres, abertos. Para Sennet (2004), isto é um mecanismo moderno de controle, dada a flexibilização do trabalho, que requer constante adaptação do trabalhador às necessidades de desempenho e controle das organizações. Entende-se por controle a existência de mecanismos de coordenação que produzem padronizações de processos por meio de instruções programadas de trabalho, limitando as ações dos indivíduos (MINTZBERG, 1995; TAYLOR, 1995). O outro lado desse contexto é que há um crescente número de trabalhadores sem laços sociais profundos e de baixa densidade ética. Paula (2005) faz a reflexão sobre como a univer- 
sidade contribui para a formação de gestores éticos, ou de valores ético-morais legitimados pela comunidade geral.

Aktouf (2001) aborda a necessidade de renovação da escola de administração, face ao excesso de práticas voltadas para o desempenho econômico financeiro, em curto prazo, cujos reflexos para os trabalhadores são da ausência do controle de vida pessoal e de suas condições de trabalho. Ele coloca a necessidade de uma visão humanista nas organizações, que contribuiria para a redução do poder unilateral, da concepção instrumental do empregado, da fragmentação do trabalho, destruindo o sentido, o significado de trabalho para o homem, tornando-o alienado e desmotivado. De certa forma, ele equipara as organizações à máquinas, pois elas necessitam de precisão, clareza, regularidade, eficiência. Para Morgan (1986), essas metáforas que auxiliam na compreensão, no entanto, levam a distorções, pois desumanizam o papel do trabalhador como um elemento de organização ou de um organismo social, que se adapta para a sua sobrevivência. Entre as adaptações para a sobrevivência das organizações e do trabalho, destaca-se a globalização da economia que introduziu a era do conhecimento, mudando as relações de produção e do significado do trabalho. $\mathrm{O}$ novo paradigma de eficiência e produtividade é o processamento das informações e de suas redes de conexões e a comunicação de símbolos (CASTELLS, 2000). É a evolução dos mecanismos de controle das organizações sob a ótica da eficiência e, também, do poder. As organizações se tornaram complexas em suas redes de relações, onde o desempenho econômico financeiro depende da adesão de seus atores sociais. Para Zarifian (2001), uma das formas foi a inserção da participação do coletivo de trabalhadores, a outra foi da formação profissional promovida pela própria organização, onde se busca a equalização da escolarização para um aproveitamento adequado das competências profissionais e, de certa forma, uma modelagem de comportamento para uma futura proposição de cultura e modus operandi daquela organização. A comunicação interna exerce um papel fundamental e deverá ser de mão dupla e verticalizada para atingir todos os níveis hierárquicos da organização, cujo objetivo é a redução das diferenças e o antagonismo de interesses (PIMENTA \& CORREA, 2006). É a presença da subjetividade, que afeta as rela- 
ções de trabalho, pessoais, e que com a globalização das economias, exige-se outras potencialidades do trabalhador, não necessariamente racionais, mas decorrentes de suas experiências, credo, cultura para que haja resolução dos problemas organizacionais e, inclusive, de desempenho econômico (DAVEL \& VERGARA, 2001).

O avanço tecnológico e, por conseguinte, a reformulação do trabalho, é um fato irreversível para a sociedade e para a classe que sobrevive da remuneração de sua força laboral. A tecnologia é concentradora de renda. Muitas nações e suas organizações não conseguem promover o equilíbrio entre tecnologia e empregos substitutos para esse evento ou redirecionamento de novas carreira. Antunes $(1999,2006)$ constatou um cenário crítico, excesso de mão de obra não somente em países emergentes, mas também para os países detentores de desenvolvimento tecnológico. O excesso de mão de obra para uma economia de baixo crescimento resulta em outras formas de trabalho, informais, flexíveis, e talvez, precários. Para Dahl (2001), Touraine (1996), o desemprego é uma expropriação de um direito do cidadão.

O Quadro 3 é um resumo do referencial teórico, base das publicações em análise nesta pesquisa, cujas teorias têm alguma referência ao tema trabalho, mas com foco nas condições atuais, e o impacto da tecnologia nessas relações. 
Quadro 3: Referências das principais teorias encontradas nos artigos sobre "Novas tecnologias e condições de trabalho"

\begin{tabular}{|c|c|c|c|c|c|}
\hline & Ano & Artigo & $\begin{array}{l}\text { Referência } \\
\text { Teórica }\end{array}$ & Abordagem & Tema abordado \\
\hline 1 & 2001 & $\begin{array}{l}\text { Administração } \\
\text { e Teorias das } \\
\text { Organizações } \\
\text { Contemporâ- } \\
\text { neas: rumo a } \\
\text { um humanismo } \\
\text {-radical crítico? }\end{array}$ & $\begin{array}{l}\text { Omar Aktouf } \\
\text { Chanlat \& Du- } \\
\text { four (1985) } \\
\text { Morgan (1986) }\end{array}$ & $\begin{array}{l}\text { Estudos Crí- } \\
\text { ticos } \\
\text { Estudos Crí- } \\
\text { ticos } \\
\text { Estudos Crí- } \\
\text { ticos }\end{array}$ & $\begin{array}{l}\text { Alienação } \\
\text { Alienação, Controle, } \\
\text { Sofrimento } \\
\text { Significado da empresa } \\
\text { e do trabalho }\end{array}$ \\
\hline 2 & 2003 & $\begin{array}{l}\text { Escritórios aber- } \\
\text { tos: interação } \\
\text { ou controle? }\end{array}$ & $\begin{array}{l}\text { Foucault (1979, } \\
1987)\end{array}$ & $\begin{array}{l}\text { Estudos Crí- } \\
\text { ticos }\end{array}$ & $\begin{array}{l}\text { Controle nas organiza- } \\
\text { ções }\end{array}$ \\
\hline \multirow[b]{2}{*}{3} & \multirow[b]{2}{*}{2005} & \multirow{2}{*}{$\begin{array}{l}\text { A inserção da } \\
\text { racionalidade } \\
\text { ético-comunica- } \\
\text { tiva nas práxis } \\
\text { empresariais: } \\
\text { possibilidades e } \\
\text { limites }\end{array}$} & Castells (2000) & $\begin{array}{l}\text { Sociologia, } \\
\text { Redes }\end{array}$ & $\begin{array}{l}\text { Economia global e tec- } \\
\text { nologia }\end{array}$ \\
\hline & & & $\begin{array}{l}\text { Guerreiro Ra- } \\
\text { mos (1989) }\end{array}$ & $\begin{array}{l}\text { Estudos Crí- } \\
\text { ticos }\end{array}$ & $\begin{array}{l}\text { Estudo das Organiza- } \\
\text { ções }\end{array}$ \\
\hline \multirow{5}{*}{4} & \multirow{5}{*}{2005} & \multirow{5}{*}{$\begin{array}{l}\text { Trabalho, } \\
\text { controle e } \\
\text { resistências nas } \\
\text { sociedades ca- } \\
\text { pitalistas: uma } \\
\text { perspectiva } \\
\text { organizacional }\end{array}$} & Taylor (1995) & $\begin{array}{l}\text { Administra- } \\
\text { ção }\end{array}$ & $\begin{array}{l}\text { Estudo das Organiza- } \\
\text { ções }\end{array}$ \\
\hline & & & Fayol (1994) & $\begin{array}{l}\text { Administra- } \\
\text { ção }\end{array}$ & $\begin{array}{l}\text { Estudo das Organiza- } \\
\text { ções }\end{array}$ \\
\hline & & & $\begin{array}{l}\text { Mintzberg } \\
(1995)\end{array}$ & $\begin{array}{l}\text { Estudos Crí- } \\
\text { ticos }\end{array}$ & $\begin{array}{l}\text { Controle nas organiza- } \\
\text { ções }\end{array}$ \\
\hline & & & $\begin{array}{l}\text { Weber (1966) } \\
\text { Sewell e } \\
\text { Wilkinson } \\
(1992)\end{array}$ & $\begin{array}{l}\text { Estudo das } \\
\text { Organizações } \\
\text { Estudos Crí- } \\
\text { ticos }\end{array}$ & $\begin{array}{l}\text { Estudo das Organiza- } \\
\text { ções } \\
\text { Controle nas organiza- } \\
\text { ções }\end{array}$ \\
\hline & & & $\begin{array}{l}\text { Sennet (2004) } \\
\text { Foucault (1987) }\end{array}$ & $\begin{array}{l}\text { Estudos Crí- } \\
\text { ticos } \\
\text { Estudos Crí- } \\
\text { ticos }\end{array}$ & $\begin{array}{l}\text { Mecanismos de controle } \\
\text { Controle nas organiza- } \\
\text { ções }\end{array}$ \\
\hline 5 & 2005 & $\begin{array}{l}\text { Desconstruin- } \\
\text { do temas e } \\
\text { estratégias da } \\
\text { Administração } \\
\text { moderna: uma } \\
\text { leitura pós-mo- } \\
\text { derna do mun- } \\
\text { do de Dilbert }\end{array}$ & $\begin{array}{l}\text { Foucault (1998) } \\
\text { Alvesson \& } \\
\text { Deetz (1999) } \\
\text { Dejours (1999) }\end{array}$ & $\begin{array}{l}\text { Estudos Crí- } \\
\text { ticos } \\
\text { Estudos Crí- } \\
\text { ticos } \\
\text { Estudos Crí- } \\
\text { ticos }\end{array}$ & $\begin{array}{l}\text { Estudo das Organiza- } \\
\text { ções } \\
\text { Estudo das Organiza- } \\
\text { ções } \\
\text { Precarização das rela- } \\
\text { ções de trabalho }\end{array}$ \\
\hline
\end{tabular}




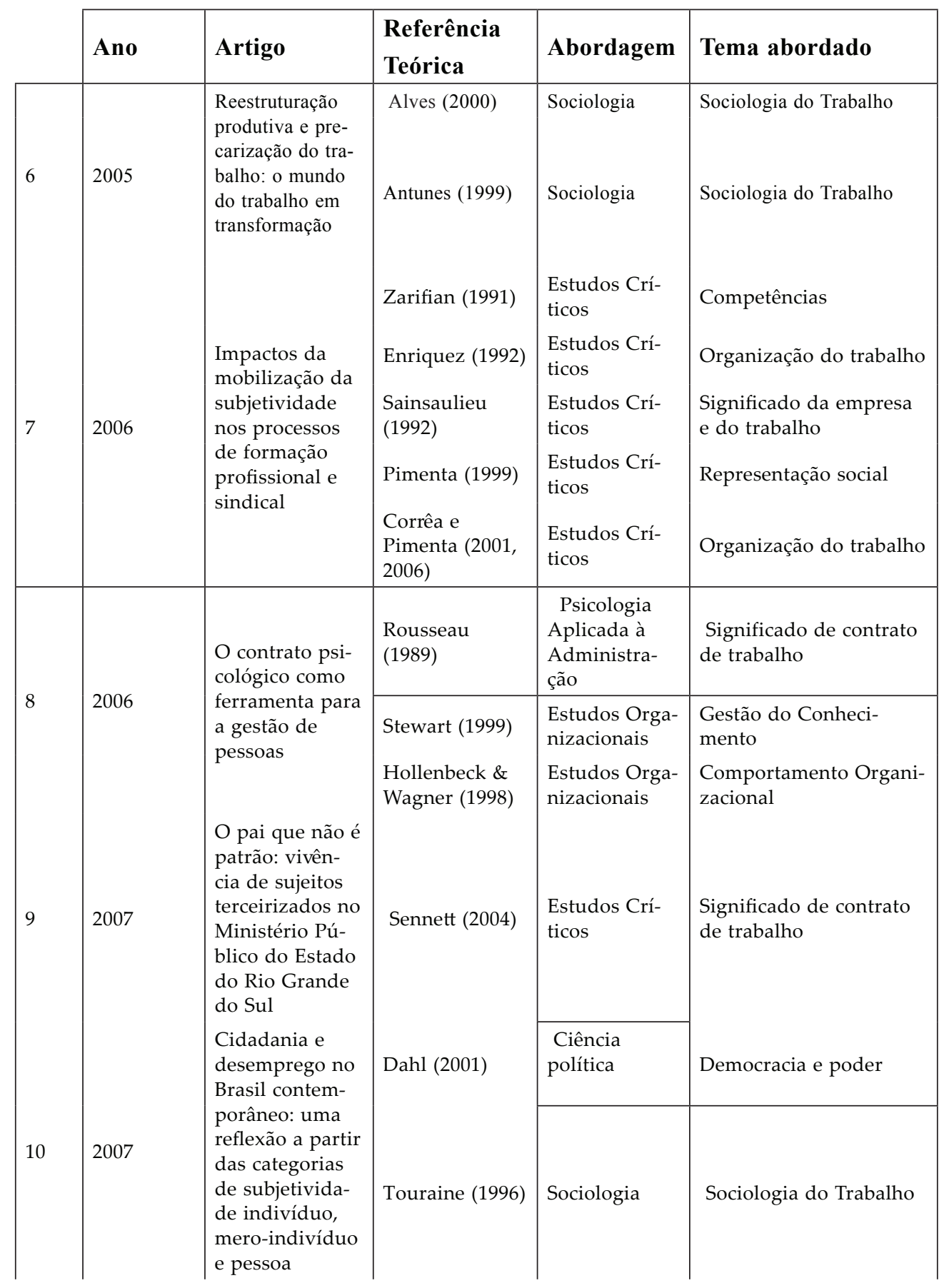




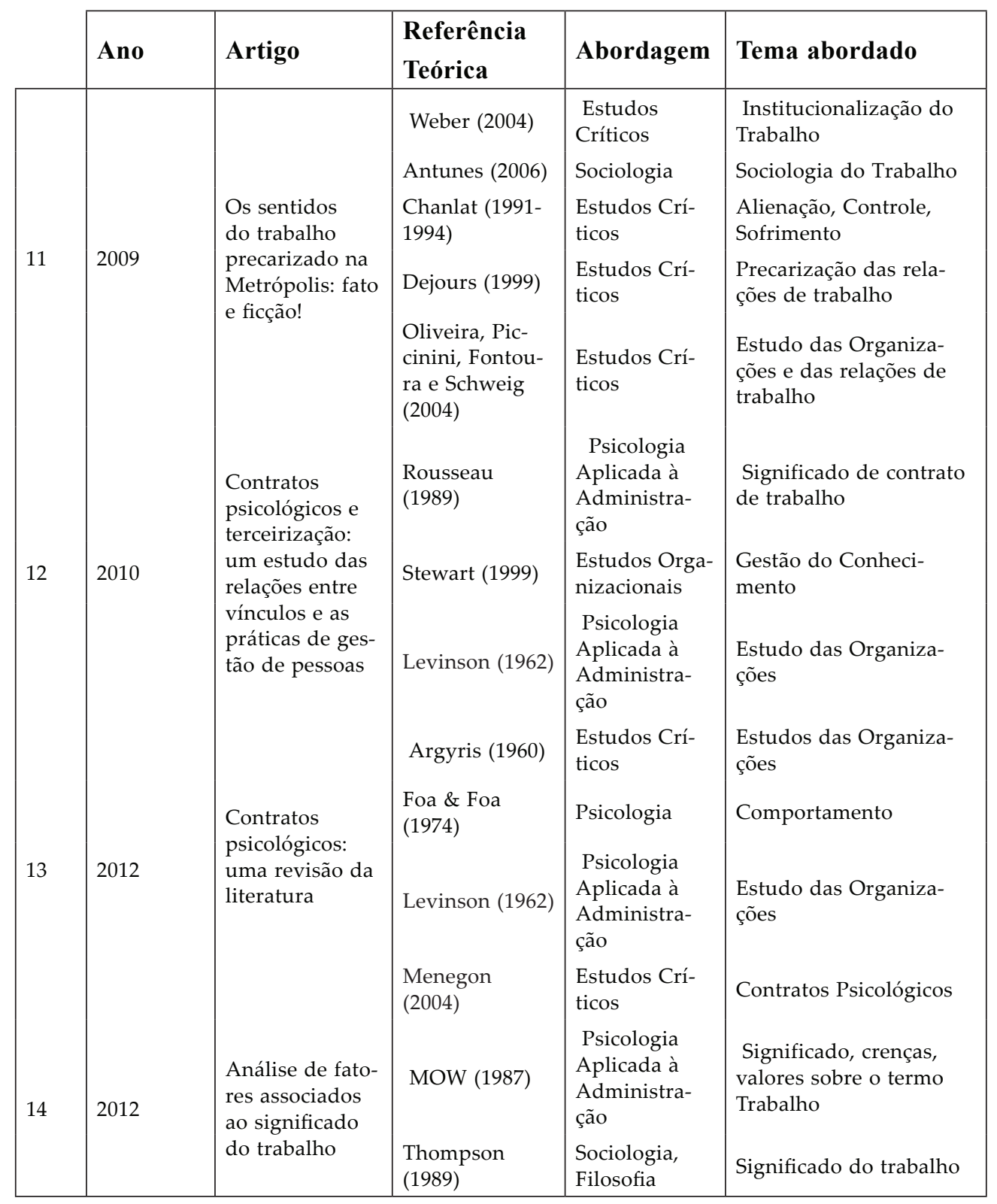




\begin{tabular}{|c|c|c|c|c|c|}
\hline & Ano & Artigo & $\begin{array}{l}\text { Referência } \\
\text { Teórica }\end{array}$ & Abordagem & Tema abordado \\
\hline 15 & 2014 & $\begin{array}{l}\text { Humor na In- } \\
\text { ternet: trabalha- } \\
\text { dores utilizam } \\
\text { nova estratégia } \\
\text { para protestar } \\
\text { contra demis- } \\
\text { sões e terceiri- } \\
\text { zações }\end{array}$ & $\begin{array}{l}\text { Bourdier } \\
(2005)\end{array}$ & $\begin{array}{l}\text { Sociologia, } \\
\text { Antropologia }\end{array}$ & Poder simbólico \\
\hline \multirow{5}{*}{16} & \multirow{5}{*}{2015} & \multirow{5}{*}{$\begin{array}{l}\text { Contratos } \\
\text { flexíveis de } \\
\text { trabalho: dife- } \\
\text { rentes perfis de } \\
\text { trabalhadores } \\
\text { qualificados } \\
\text { brasileiros }\end{array}$} & Castells (2000) & $\begin{array}{l}\text { Sociologia, } \\
\text { Redes }\end{array}$ & $\begin{array}{l}\text { Economia global e tec- } \\
\text { nologia }\end{array}$ \\
\hline & & & Toni, M. (2006) & Sociologia & $\begin{array}{l}\text { Precarização das rela- } \\
\text { ções de trabalho }\end{array}$ \\
\hline & & & $\begin{array}{l}\text { Piccinini, Oli- } \\
\text { veira \& Rübe- } \\
\text { nich }(2006)\end{array}$ & $\begin{array}{l}\text { Estudos Crí- } \\
\text { ticos }\end{array}$ & $\begin{array}{l}\text { Estudo das Organiza- } \\
\text { ções e das relações de } \\
\text { trabalho }\end{array}$ \\
\hline & & & $\begin{array}{l}\text { Antunes (2002, } \\
2006)\end{array}$ & Sociologia & Sociologia do Trabalho \\
\hline & & & $\begin{array}{l}\text { Costa, M. S. } \\
(2003,2007)\end{array}$ & Sociologia & Autonomia e Controle \\
\hline
\end{tabular}

Fonte: preparado pelos autores

Os resultados da terceira etapa demonstram um número reduzido de publicações nas RAC, RAE-Eletrônica, RAP, RAUSP e O\&S, bem como da utilização de um histórico de pesquisas para a composição do referencial teórico e para a construção da argumentação da pesquisa. Isto é para contextualizar as relações do trabalho ao longo do tempo, acrescendo outros fatos, características recentes sobre as novas formas de ocupação do trabalho e as suas condições.

Dado os resultados, procedeu-se ao levantamento das citações, através da ferramenta Google Citations com o objetivo de comparar as citações dos autores que compõem o h5 index das revistas RAC, RAE-Eletrônica, RAP, RAUSP e O\&S, por conseguinte do impacto das publicações em análise. O Quadro 4, a seguir, são as citações das publicações do presente estudo. 
Quadro 4: Referências das principais teorias encontradas nos artigos sobre "Novas tecnologias e condições de trabalho"

\begin{tabular}{|c|c|c|c|c|c|}
\hline & Título & Autores & $\begin{array}{l}\text { Perió- } \\
\text { dico }\end{array}$ & Ano & $\begin{array}{l}\text { №. Cita- } \\
\text { ções }\end{array}$ \\
\hline 1 & $\begin{array}{l}\text { Administração e Teorias das } \\
\text { Organizações Contemporâ- } \\
\text { neas: rumo a um humanismo } \\
\text {-radical crítico? }\end{array}$ & Omar Aktouf & O\&S & 2001 & 30 \\
\hline 2 & $\begin{array}{l}\text { Escritórios abertos: interação } \\
\text { ou controle? }\end{array}$ & $\begin{array}{l}\text { Sylvia Constant } \\
\text { Vergara, Ana Pau- } \\
\text { la Cortat Zambro- } \\
\text { tti Gomes }\end{array}$ & RAP & 2003 & 3 \\
\hline 3 & $\begin{array}{l}\text { A inserção da racionalidade } \\
\text { ético-comunicativa na práxis } \\
\text {-empresarial: possibilidades e } \\
\text { limites }\end{array}$ & $\begin{array}{l}\text { Reynaldo Josué de } \\
\text { Paula }\end{array}$ & O\&S & 2005 & - \\
\hline 4 & $\begin{array}{l}\text { Trabalho, controle e resistên- } \\
\text { cias nas sociedades capitalis- } \\
\text { tas: uma perspectiva organi- } \\
\text { zacional }\end{array}$ & $\begin{array}{l}\text { Jean Martins de } \\
\text { Souto, Rúbia da } \\
\text { Silva }\end{array}$ & O\&S & 2005 & 1 \\
\hline 5 & $\begin{array}{l}\text { Desconstruindo temas e } \\
\text { estratégias da Administração } \\
\text { moderna: uma leitura pós-mo- } \\
\text { derna do mundo de Dilbert }\end{array}$ & $\begin{array}{l}\text { Neusa Rolita } \\
\text { Cavedon, Jorge } \\
\text { Francisco Bertinet- } \\
\text { ti Lengler }\end{array}$ & O\&S & 2005 & 1 \\
\hline 6 & $\begin{array}{l}\text { Reestruturação produtiva e } \\
\text { precarização do trabalho: o } \\
\text { mundo do trabalho em trans- } \\
\text { formação }\end{array}$ & $\begin{array}{l}\text { José Henrique de } \\
\text { Faria, Antonio } \\
\text { Kremer }\end{array}$ & RAUSP & 2005 & 19 \\
\hline 7 & $\begin{array}{l}\text { Impactos da mobilização da } \\
\text { subjetividade nos processos } \\
\text { de formação profissional e } \\
\text { sindical }\end{array}$ & $\begin{array}{l}\text { Maria Leticia Cor- } \\
\text { rêa, Solange Maria } \\
\text { Pimenta }\end{array}$ & $\begin{array}{l}\text { RAEle- } \\
\text { tronica }\end{array}$ & 2006 & 5 \\
\hline 8 & $\begin{array}{l}\text { O contrato psicológico como } \\
\text { ferramenta para a gestão de } \\
\text { pessoas }\end{array}$ & $\begin{array}{l}\text { Leticia Fantinato } \\
\text { Menegon, Tania } \\
\text { Casado }\end{array}$ & RAUSP & 2006 & 20 \\
\hline 9 & $\begin{array}{l}\text { O pai que não é patrão: vivên- } \\
\text { cia de sujeitos terceirizados no } \\
\text { Ministério Público do Estado } \\
\text { do Rio Grande do Sul }\end{array}$ & $\begin{array}{l}\text { Silvia Generali da } \\
\text { Costa }\end{array}$ & O\&S & 2007 & 4 \\
\hline 10 & $\begin{array}{l}\text { Cidadania e desemprego no } \\
\text { Brasil contemporâneo: uma } \\
\text { reflexão a partir das categorias } \\
\text { de subjetividade do indivíduo, } \\
\text { mero-indivíduo e pessoa }\end{array}$ & $\begin{array}{l}\text { Maria Cecília Pe- } \\
\text { reira, José Roberto } \\
\text { Pereira, Mozar } \\
\text { José de Brito }\end{array}$ & O\&S & 2007 & 2 \\
\hline
\end{tabular}




\begin{tabular}{|c|c|c|c|c|c|}
\hline & Título & Autores & $\begin{array}{l}\text { Perió- } \\
\text { dico }\end{array}$ & Ano & $\begin{array}{l}\text { No. Cita- } \\
\text { ções }\end{array}$ \\
\hline 11 & $\begin{array}{l}\text { Os sentidos do trabalho pre- } \\
\text { carizado na Metrópolis: fato } \\
\text { e ficção! }\end{array}$ & $\begin{array}{l}\text { Sérgio Carvalho } \\
\text { Benício de Mello, } \\
\text { Maria Christianni } \\
\text { Coutinho Marçal, } \\
\text { Francisco Ricardo } \\
\text { Bezerra Fonsêca }\end{array}$ & O\&S & 2009 & 6 \\
\hline 12 & $\begin{array}{l}\text { Contratos psicológicos e } \\
\text { terceirização: um estudo das } \\
\text { relações entre vínculos e as } \\
\text { práticas de gestão de pessoas }\end{array}$ & $\begin{array}{l}\text { Mino Correia } \\
\text { Rios, Sônia Maria } \\
\text { Guedes Gondim }\end{array}$ & O\&S & 2010 & 3 \\
\hline 13 & $\begin{array}{l}\text { Contratos psicológicos: uma } \\
\text { revisão da literatura }\end{array}$ & $\begin{array}{l}\text { Leticia Fantinato } \\
\text { Menegon, Tania } \\
\text { Casado }\end{array}$ & RAUSP & 2012 & 10 \\
\hline 14 & $\begin{array}{l}\text { Análise de fatores associados } \\
\text { ao significado do trabalho }\end{array}$ & $\begin{array}{l}\text { Sergio Hideo } \\
\text { Kubo, Maria Apa- } \\
\text { recida Gouvêa }\end{array}$ & RAUSP & 2012 & 20 \\
\hline 15 & $\begin{array}{l}\text { Humor na Internet: trabalha- } \\
\text { dores utilizam nova estratégia } \\
\text { para protestar contra demis- } \\
\text { sões e terceirizações }\end{array}$ & $\begin{array}{l}\text { Raquel Alves } \\
\text { Furtado, Alexandre } \\
\text { de Pádua } \\
\text { Carrieri, Paula } \\
\text { Fernandes } \\
\text { Furbino Bretas }\end{array}$ & RAUSP & 2014 & 3 \\
\hline 16 & $\begin{array}{l}\text { Contratos flexíveis de tra- } \\
\text { balho: diferentes perfis de } \\
\text { trabalhadores qualificados } \\
\text { brasileiros }\end{array}$ & $\begin{array}{l}\text { Marcia Carvalho } \\
\text { de Azevedo, Ma- } \\
\text { ria José Tonel- } \\
\text { li, André Luis } \\
\text { Silva }\end{array}$ & RAUSP & 2015 & - \\
\hline
\end{tabular}

Fonte: preparado pelos autores

H5-index é uma métrica disponível no Google Citation, que mede o número de citações feitas de determinado pesquisador por um período de cinco anos. O Quadro 6, a seguir, demonstra o resultado das informações disponíveis sobre o H5-index, bem como, o maior (menor) número de citações de um autor. Com base nessas informações, é possível estabelecer uma relação entre as citações dos artigos em análise e corroborar para com o entendimento de que as pesquisas sobre estudos críticos relativos nas condições atuais e o impacto da tecnologia nessas relações em revistas especializadas em administração são reduzidas, bem como, as citações, quando 
comparadas a outras áreas de estudo, por exemplo: finanças, gestão, marketing etc. Contudo, estão dentro do limítrofe inferior do número de citações demonstradas no Quadro 5.

Quadro 5: H5 index das Revistas RAC, RAE-Eletrônica, RAP, RAUSP e OES

\begin{tabular}{|l|l|l|l|}
\cline { 3 - 4 } \multicolumn{2}{c|}{} & \multicolumn{2}{l|}{ №. Citações } \\
\hline Periódico & H5-index: & $>$ & $<$ \\
\hline O\&S & 10 & 54 & 10 \\
\hline RAP & 16 & 47 & 16 \\
\hline RAC & Não disponível & Idem & Ibidem \\
\hline RAE-Eletrônica & Não disponível & 13 & 2 \\
\hline RAUSP & 8 & 42 & 9 \\
\hline
\end{tabular}

Fonte: preparado pelos autores

\section{CONSIDERAÇõES FINAIS}

A importância ou a significação do trabalho para o indivíduo tornou-se objeto de estudo, a partir da mudança das características do trabalho ao longo do tempo. A sociedade ancorada na tecnologia da informação trouxe novas perspectivas sobre o trabalho e nos meios de produção.

Estudos Críticos a respeito do tema: as novas formas de ocupação do trabalho e as suas condições são constantemente estudadas dado o processo de reestruturação das organizações para a busca de desempenho econômico financeiro sustentável. Novas relações de trabalho são acomodadas, mas não indicam necessariamente melhorias para o indivíduo. Em grande parte, representam formas modernas de controle e redução da autonomia do trabalhador na organização. A discussão acerca do trabalho é longínqua, não restrita, histórica e cumulativa, corroborando para o entendimento da forma de construção da argumentação de grande parte das pesquisas.

O procedimento metodológico deste estudo demonstrou que há em média cerca de 500 publicações nas revistas RAC, RAE-Eletrônica, RAP, RAUSP e O\&S, mas há um reduzido número de pesquisas sobre estudos das organizações com viés crítico a respeito 
do tema trabalho. Outro dado relevante é acerca das citações dos autores que, em grande parte, se encontram no limítrofe inferior do número de citações para os últimos cinco anos. Esses resultados não diferem estatisticamente daqueles publicados em 2000, na Revista de Administração $(R A e)$, por Davel e Alcadipany em os Estudos Críticos em Administração: a produção científica brasileira nos anos 1990. Assim como a pergunta de pesquisa feita por Boaventura de Souza Santos: Por que é tão difícil construir uma teoria crítica? (1999) Com certeza, não é porque não temos o que criticar. Certamente, para o indivíduo que tem seu tempo alocado, em boa parte, em trabalhos desenvolvidos nas organizações, com isto, teria temas relevantes para pesquisa e contribuição com os estudos críticos, contudo, não se observa tal fato.

As pesquisas de cunho crítico, de emancipação do indivíduo, são estudos empíricos. Já os estudos de caso ou de aplicação, em grande parte, versam sobre melhorias, padrões a serem estabelecidos nas organizações para o alcance de desempenho, construção de imagem, mitigação de problemas etc. Talvez, o poder disciplinar panóptico de Benthan (2000) transformou a categoria trabalho em uma opressão consentida.

O trabalho tem centralidade significativa na vida de um indivíduo, pois é partir dele que há os rendimentos econômicos para a sua sobrevivência. Em paralelo, o desenvolvimento econômico transforma essas relações e produz revoluções das estruturas, assim, admite-se a possibilidade de uma $4 .^{\text {a }}$ Revolução Industrial para os próximos 30 anos. Os principais impactos são de concentração de renda, rearranjo das relações de trabalho e crescente desemprego.

Finalmente, corrobora-se o entendimento de que, embora haja um volume significativo de pesquisas sobre Teoria Crítica a partir de 2000, assim como observado por De Paula et al. (2010) e Davel \&Alcapdipany (2000), não é possível afirmar que há uma corrente crítica e independente no Brasil.

\section{REFERÊNCIAS}

AKTOUF, O. (2001). Administração e teorias das organizações contemporâneas: rumo a um humanismo radical crítico? Organizações e Sociedade, v. 8, n. 21, p. 13-33. 
ALVES, G. (2000). O novo (e precário) mundo do trabalho - reestruturação produtiva e crise do sindicalismo. São Paulo: Boitempo Editorial / FAPESP.

ALVESSON, M. \& DEETZ, S. (1999). Teoria crítica e abordagens pós-modernas para estudos organizacionais. In: CLEGG, S.; HARDY, C. e NORD, W. Handbook de estudos organizacionais. Modelos de análise e novas questões em estudos organizacionais, v. 1. São Paulo: Atlas (Organizadores da Edição brasileira: CALDAS, M.; FACHIN, R. \& FISCHER, T.

ANTUNES, R., 1999). Os sentidos do trabalho: ensaio sobre a afirmação e a negação do trabalho, 1. ed. São Paulo.

ANTUNES, R. (2002). Adeus ao trabalho? Ensaio sobre as metamorfoses e a centralidade do mundo do trabalho. São Paulo: Cortez.

. (2006). Os sentidos do trabalho: ensaio sobre a afirmação e a negação do trabalho, 8. ed. São Paulo.

ANTUNES, R. (2006). Riqueza e miséria do trabalho no Brasil. São Paulo: Boitempo Editorial.

ARGYRIS, C. (1960). Understanding organizational behaviour. Homewood, IL: Dorsey.

BENÍCIO DE MELLO, S. C.; MARÇAL, M. C., FONSECA, F. R. B. (2009). Os sentidos do trabalho precarizado na Metropolis: fato e ficção! Salvador: O\&S, v. 16, n. 49, p. 307-323.

BENTHAM, J. (2000). O panóptico. Belo Horizonte: Autêntica.

BION, W. R. (1975). Experiências com grupos: os fundamentos da psicoterapia de grupo. Imago. BOAVENTURA, S. S. (1999). Por que é tão difícil construir uma teoria crítica? Revista de Ciências Sociais, n. 54, jun., Faculdade de Economia da Universidade de Coimbra e Centro de Estudos Sociais.

BOURDIEU, P. (2005). O poder simbólico. Rio de Janeiro: Bertrand Brasil.

CASTELLS, M. (2000). A sociedade em rede - volume I. Trad. Roneide Venâncio Majer com a colaboração de Klauss Brandini Gerhardt, v. 9.

CAVALCANTE, G. M. M., \& PRÉDES, R. (2010). A precarização do trabalho e das políticas sociais na sociedade capitalista: Fundamentos da precarização do trabalho de assistente social. Libertas, 10 (1), 1-24.

CHANLAT, A. \& DUFOUR, M. (1985). La rupture entre l'entreprise et les hommes. Montréal: Québec-Amérique.

CHANLAT, J. F. (1991-1994). O indivíduo na organização: dimensões esquecidas. São Paulo: Atlas, v. 3.

CORREA, M. L.; PIMENTA, S. M. (2006). Impactos da mobilização da subjetividade nos processos de formação profissional e sindical. RAE Eletronica, v. 5, n. 1.

COSTA, M. DA S. (2003). Reestruturação produtiva, sindicatos e a flexibilização das relações do trabalho no Brasil. RAE - Eletrônica, 2 (2), 1-16.

COSTA, M. DA S. (2007). Relações de trabalho e regimes de emprego no Canadá e no Brasil - um estudo comparativo. RAE - Eletrônica, 6 (2).

DAHL, R. A. (2001). Sobre a democracia. Brasília, EdUnB, 230p.

DAVEL, E. ALCADIPANY, R. (2000). Estudos críticos em administração: a produção científica brasileira nos anos 1990. RAE, v. 43, n. 4 . 
DAVEL, E.; VERGARA, S. C. (2001). (Org.). Gestão com pessoas e subjetividade. São Paulo: Atlas, p. 313.

DA COSTA, S. G. (2007). O pai que não é patrão: vivência de sujeitos terceirizados no Ministério Público do Estado do Rio Grande do Sul. Revista Brasileira de Ciências Sociais, v. 14, n. 42.

DE PAULA, A. P. P. et al. (2010). A tradição e a autonomia dos estudos organizacionais no Brasil. Revista de Administração de Empresas, v. 50, n. 1, p. 10.

DEJOURS, C. (1999). A banalização da injustiça social. Rio de Janeiro: Fundação Getúlio Vargas.

ENRIQUEZ, E. (1992). L'entreprise comme lien social: 'un colosse aux pieds d'argile'. In: SAINSAULIEU, R. L'entreprise, une affaire de société. Paris: Presses de la Fondation Nationale des Sciences Sociales.

FAYOL, H. Administração industrial e geral: previsão, organização, comando, coordenação, controle, 10. ed. São Paulo: Atlas, 1994.

FOA, U. G.; FOA, E. B. (1974). Societal structures of the mind. Springfield, IL: Charles C. Thomas.

FOUCAULT, M. (1987). Vigiar e punir, 20. ed. Petrópolis: Vozes.

FOUCAULT, M. (1998). A ordem do discurso, 4. ed. São Paulo: Loyola.

FOURNIER, V. e GREY, C. (2000). At the critical moment: conditions and prospects for critical management studies. Human Relations, v. 53, n. 1, p. 7-32.

GUERREIRO RAMOS, A. (1981, 1989). A nova ciência das organizações: uma reconceituação da Riqueza das Nações, 2. ed. Rio de Janeiro: Editora da FGV.

HOLLENBECK \& WAGNER (1998). Organizational behavior: securing competitive advantage. Upper Saddle River. New Jersey: Prentice-Hall.

LEVINSON, H. et al. (1962). Men, management and mental health. Cambridge, MA: Harvard University Press.

MENEGON, L. F. (2004). Contratos psicológicos como fatores influenciadores dos índices de rotatividade voluntária em empresas de consultoria, 2004. Dissertação (Mestrado) - Faculdade de Economia, Administração e Contabilidade da Universidade de São Paulo, São Paulo, São Paulo, Brasil.

MINTZBERG, H. Criando organizações eficazes: estruturas em cinco configurações. São Paulo: Atlas, 1995.

MORGAN, G. (1986). Images of Organizations. Beverly Hills: Sage Publications.

MOW - (1987). International Research Team. The meaning of working. London: Academic Press.

OLIVEIRA, S.; PICCININI, V. C.; FONTOURA, D. S.; SCHWEIG, C. (2004). Buscando o sentido do trabalho. Encontro Nacional de Programas de Pós-Graduação em Administração, 28, Curitiba-PR. Anais... Curitiba-PR, ANPAD.

PAULA, R. J. de. (2005). A inserção da racionalidade ético-comunicativa na práxis empresarial: possibilidades e limites. Organizações \& Sociedade, v. 12, n. 35, p. 29-45.

PICCININI, V. C., OLIVEIRA, S. R., \& RÜBENICH, N. V. (2006). Formal, flexível ou informal? 
Reflexões sobre o trabalho no Brasil. In: V. C. Piccinni, L. Holzmann, I. Kovacs, \& V. N. Guimarães (Org.). (2006). O mosaico do trabalho na sociedade contemporânea (p. 93-118). Porto Alegre: Editora da UFRG.

PIMENTA, S. M. (1999). A estratégia da gestão na nova ordem das empresas. In: PIMENTA, S. M. (Org.). Recursos Humanos: uma dimensão estratégica. Belo Horizonte: UFMG / FACE / Cepead.

PIMENTA, S. M.; CORRÊA, M. L. (2001) (Orgs.). Gestão, trabalho e cidadania: novas articulações. Belo Horizonte: Autêntica / Cepead / UFMG.

PIMENTA, S. M.; CORRÊA, M. L. (2006). Fórum - Novos Modelos Organizacionais: paradoxos e contradições entre o discurso e a prática impactos da mobilização da subjetividade nos processos de formação profissional e sindical, RAE- eletrônica, v. 5, n. 1, jan./jun.

ROUSSEAU, D. M. (1989). Psychological and implied contracts in organizations. Employee Responsibilities and Rights Journal, v. 2, n. 2, p. 121-139.

SAINSAULIEU, R. (1992) (Org.). L'entreprise, une affaire de société. Paris: Presses de la Fondation Nationale des Sciences Politiques.

SEWELL, G.; WILKINSON, B. (1992). 'Someone to watch over me': surveillance, discipline and the just in time labour process. Sociology, v. 26, n. 2, p. 271-289.

SENNET, R. (1998). O declínio do Homem Público: as tiranias da intimidade. São Paulo, Companhia das Letras.

SENNET, R. (2004). A corrosão do Caráter: as consequências pessoais do trabalho no novo capitalismo. Rio de Janeiro: Record.

STEWART, T. A. (1999). Intellectual capital: the new wealth of organizations, 2. ed. New York: Currency Doubleday.

TAYLOR, F. W. Princípios de administração científica. São Paulo: Atlas, 1995.

THOMPSON, P. (1989). The Nature of Work: An Introduction to Debates on the Labour Process, 2. ed. London: Palgrave.

TONI, M. (2006). Mutações do trabalho no Brasil: Abordagens interpretativistas. Ensaios FEE, 27(2), 437-470.

TOURAINE, A. O que é a democracia. Petrópolis: Vozes, 1996, 286p.

VERGARA, S. C.; CORTAT ZAMBROTTI GOMES, A. P. (2003). Escritórios abertos: interação ou controle? Rio de Janeiro: RAP 37 (4): 817-35.

WEBER, M. Sociologia da burocracia. Rio de Janeiro: Zahar, 1966.

ZARIFIAN, P. (2001). Comunicação e subjetividade nas organizações. In: DAVEL, E.; VERGARA, S. Gestão com pessoas e subjetividade. São Paulo: Atlas.

Recebido em: 12-5-2017

Aprovado em: 30-08-2017

Avaliado pelo sistema double blind review.

Editor: Elmo Tambosi Filho

Disponível em http://mjs.metodista.br/index.php/roc 